The University of Maine

\title{
DigitalCommons@UMaine
}

Earth Science Faculty Scholarship

Earth Sciences

8-20-2004

\section{Sea Level Pressure Variability Over the Southern Indian Ocean Inferred from a Glaciochemical Record in Princess Elizabeth Land, East Antarctica}

Cunde Xiao

Paul Andrew Mayewski

University of Maine - Main, paul.mayewski@maine.edu

Dahe Qin

Zhongqin Li

Mingjun Zhang

See next page for additional authors

Follow this and additional works at: https://digitalcommons.library.umaine.edu/ers_facpub

Part of the Earth Sciences Commons

\section{Repository Citation}

Xiao, Cunde; Mayewski, Paul Andrew; Qin, Dahe; Li, Zhongqin; Zhang, Mingjun; and Yan, Yuping, "Sea Level Pressure Variability Over the Southern Indian Ocean Inferred from a Glaciochemical Record in Princess Elizabeth Land, East Antarctica" (2004). Earth Science Faculty Scholarship. 78.

https://digitalcommons.library.umaine.edu/ers_facpub/78

This Article is brought to you for free and open access by DigitalCommons@UMaine. It has been accepted for inclusion in Earth Science Faculty Scholarship by an authorized administrator of DigitalCommons@UMaine. For more information, please contact

um.library.technical.services@maine.edu. 


\section{Authors}

Cunde Xiao, Paul Andrew Mayewski, Dahe Qin, Zhongqin Li, Mingjun Zhang, and Yuping Yan 


\title{
Sea level pressure variability over the southern Indian Ocean inferred from a glaciochemical record in Princess Elizabeth Land, east Antarctica
}

\author{
Cunde Xiao, ${ }^{1,2}$ Paul A. Mayewski, ${ }^{3}$ Dahe Qin, ${ }^{4}$ Zhongqin Li, ${ }^{4}$ \\ Mingjun Zhang, ${ }^{4}$ and Yuping Yan $^{3}$ \\ Received 11 August 2003; revised 25 May 2004; accepted 18 June 2004; published 20 August 2004.
}

[1] A 250-year, high-resolution, multivariate ice core record from LGB65 $\left(70^{\circ} 50^{\prime} 07^{\prime \prime} \mathrm{S}\right.$, $77^{\circ} 04^{\prime} 29^{\prime \prime} \mathrm{E} ; 1850 \mathrm{~m}$ asl), Princess Elizabeth Land (PEL), is used to investigate sea level pressure (SLP) variability over the southern Indian Ocean (SIO). Empirical orthogonal function (EOF) analysis reveals that the first EOF (EOF1) of the glaciochemical record from LGB65 represents most of the variability in sea salt throughout the 250-year record. EOF1 is negatively correlated ( $95 \%$ confidence level and higher) to instrumental mean sea level pressure (MSLP) at Kerguelen and New Amsterdam islands, SIO. On the basis of comparison with NCEP/NCAR reanalysis, strong correlations were found between sea-salt variations and a quasi-stationary low that lies to the north of Prydz Bay, SIO. Comparison with a 250-year-long summer transpolar index (STPI) inferred from subAntarctic tree ring records reveals strong coherency. Decadal-scale SLP variability over SIO suggests shifting of the polar vortex. Prominent decadal-scale deepening of the southern Indian Ocean low (SIOL) exists circa 1790, 1810, 1835, 1860, 1880, 1900, and 1940 A.D., continuously after the 1970s, and prominent weakening circa 1750, 1795, $1825,1850,1870,1890,1910$, and 1955 A.D. The LGB65 sea-salt record is characterized by significant decadal-scale variability with a strong $\sim 21$-year periodic structure (99.9\% confidence level). The relationship between LGB65 sea salt and solar irradiance changes shows that this periodicity is possibly the solar Hale cycle (22 years). INDEX TERMS: 0312 Atmospheric Composition and Structure: Air/sea constituent fluxes (3339, 4504); 1650 Global Change: Solar variability; 1620 Global Change: Climate dynamics (3309); 1863 Hydrology: Snow and ice (1827); 9310 Information Related to Geographic Region: Antarctica; KEYWORDS: ice core, east Antarctica, southern Indian Ocean, SLP, polar vortex

Citation: Xiao, C., P. A. Mayewski, D. Qin, Z. Li, M. Zhang, and Y. Yan (2004), Sea level pressure variability over the southern Indian Ocean inferred from a glaciochemical record in Princess Elizabeth Land, east Antarctica, J. Geophys. Res., 109, D16101, doi:10.1029/2003JD004065.

\section{Introduction}

[2] Deep ice core studies from Antarctica offer one of the most promising insights into the climate enigmas of Earth over the past hundreds to tens of thousands of years [e.g., Petit et al., 1999]. However, regional differences are found among decadal to centennial-scale climatic records from various sites over the Antarctic ice sheet [MosleyThompson, 1992], notably inverse trends in both temperature and accumulation [Thompson and Solomon, 2002; van den Broeke, 2000; Xiao et al., 2001]. To resolve the significance

\footnotetext{
${ }^{1}$ Chinese Academy of Meteorological Science, Beijing, China.

${ }^{2}$ Also at Cold and Arid Regions Environmental and Engineering Research Institute, Chinese Academy of Sciences, Lanzhou, China.

${ }^{3}$ Climate Change Institute, University of Maine, Orono, Maine, USA.

${ }^{4}$ Cold and Arid Regions Environmental and Engineering Research Institute, Chinese Academy of Sciences, Lanzhou, China.
}

Copyright 2004 by the American Geophysical Union. 0148-0227/04/2003JD004065 of regional and temporal variability in the Antarctic climate system the International Trans-Antarctic Scientific Expedition (ITASE) [Mayewski and Goodwin, 1999] is focusing on the collection and interpretation of ice core records covering the last $\sim 200$ years of Antarctic climate change.

[3] Previous ice core studies [e.g., Peel and Mulvaney, 1992; Kreutz et al., 2000] and recent years' ITASE investigations [e.g., Isaksson et al., 1996; Souney et al., 2002; Meyerson et al., 2002] reveal ocean/atmospheric interactions characterized by changes in sea level pressure (SLP), meridional and zonal wind strength, sea ice extent, position and strength of cyclones.

[4] Ice core studies over the region encompassed by Princess Elizabeth Land (PEL) are scarce. Since 1996, Chinese ITASE investigations have been carried out along a traverse line from Zhongshan Station toward Dome Argus (Dome A) (Figure 1). A series of ice cores have been extracted in order to reveal the past centennial to millennial-scale climate history of the region [Qin et al., 2000]. This paper gives the first interpretation of a glaciochemical series 


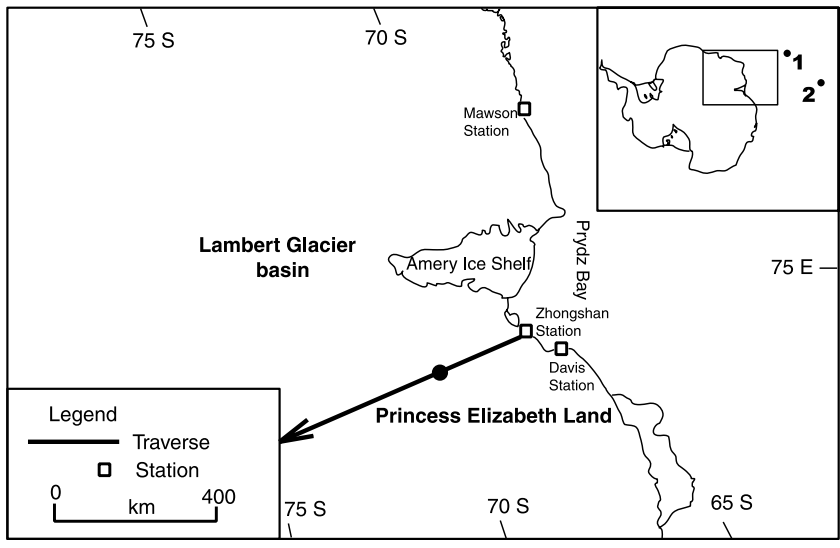

Figure 1. Location map of Chinese ITASE traverse and LGB65 ice core. Numbers 1 and 2 represent two meteorological stations in the SIO, Kerguelen Island and New Amsterdam Island, respectively.

recovered from the LGB65 ice core, PEL, and the relationship between these series and variations of SLP over the Southern Indian Ocean (SIO) and features of large-scale Southern Hemisphere (SH) circulation.

\section{Data}

[5] The glaciochemical $\left(\mathrm{Na}^{+}, \mathrm{Mg}^{2+}, \mathrm{K}^{+}, \mathrm{Ca}^{2+}, \mathrm{Cl}^{-}, \mathrm{NO}_{3}^{-}\right.$ and $\mathrm{SO}_{4}^{2-}$ ), accumulation rate, and oxygen isotope ratio series used in this study (Figure 2) come from a 252-yearlong (1745-1996 A.D.) $51.85 \mathrm{~m}$ ice core (LGB65, accumulation rate $127 \mathrm{~kg} \mathrm{~m}^{-2} \mathrm{a}^{-1}$, mean annual temperature $-33^{\circ} \mathrm{C}$ ) [Li et al., 1999; Qin et al., 2000; Xiao et al., 2001]. The ice core was analyzed via suppressed ion chromatography at the Laboratory of Ice Core and Cold Regions Environment, Chinese Academy of Sciences. Oxygen isotope analyses $\left(\delta^{18} \mathrm{O}\right)$ were performed using a Finnigan MAT-252 spectrometer (with accuracy 0.05\%). Cations were analyzed with a Dionex CS12 column, $500 \mu \mathrm{L}$ loop, and $22 \mathrm{mM}$ MSA eluent and anions were analyzed with a Dionex AS4A-GC column, $500 \mu \mathrm{L}$ loop, and $1.7 \mathrm{mM}$ $\mathrm{NaHCO}_{3} / 1.8 \mathrm{mM} \mathrm{Na} \mathrm{CO}_{3}$ eluent [Curran and Palmer, 2001]. All samples were melted at room temperature in sealed polyethylene containers immediately prior to analysis.

[6] The depth-age scale developed for LGB65 ice core is based on the seasonal signature of the oxygen isotope ratio (for the uppermost 10 meters, containing 40 years) and glaciochemical profiles for the whole depth [Li et al., 1999]. Independent depth-age control is provided by volcanic $\mathrm{SO}_{4}^{2-}$ reference horizons of known age [Zhang et al., 2002]. A similar number of volcanic events have been detected over the last 250 years at other east Antarctic sites (e.g., Talos Dome and Law Dome) [Palmer et al., 2001; Stenni et al., 2002]. On the basis of the depth-age scale developed for LGB65 core, the sampling resolution for the 252-year-long glaciochemical record used in this study is 5-14 samples per year. The accumulated errors, attributable to a few ambiguous seasonal cycles, are estimated to be \pm 3 years at the end of the record and less than 1 year over the period $1940-1996$ etails in the work of $\mathrm{Li}$ et al.
[1999]), corresponding to the period for SLP/ice core calibration in this study. The accuracy of the dating is confirmed by the identification of major volcanic eruptions such as Tambora (1815 A.D.), Krakatoa (1883 A.D.) and Tarawera (1886 A.D.) dated in the ice core at 1817, 1884 and 1886 respectively. A second ice core was drilled 2 meters from LGB65 during the same season and dated independently to 243 years, revealing features consistent with our record [Wen et al., 2001].

[7] Instrumental air temperature and air pressure data from the longest records in the high latitude SIO Kerguelen Island $\left(49^{\circ} 21^{\prime} \mathrm{S}, 70^{\circ} 12^{\prime} \mathrm{E}\right)$ and New Amsterdam Island $\left(37^{\circ} 50^{\prime} \mathrm{S}, 77^{\circ} 34^{\prime} \mathrm{E}\right)$, as well as the closest station at coast, Davis $\left(68^{\circ} 35^{\prime} \mathrm{S}, 77^{\circ} 58^{\prime} \mathrm{E}\right)$ (Figure 1) are readily available (see http://www.antcrc.utas.edu.au/ jacka/climate.html). Observations at Kerguelen Island started in 1951, but contain gaps from 1986-1988 and 1992-1995 for air temperature, and 1951, 1974, 1989-1996 for air pressure. At New Amsterdam Island, continuous records are available between 1951-1985 for air temperature, and 1951-1986 for air pressure with a gap in 1974. At Davis, air pressure and air temperature records are available for 1958-1991 excepting a gap from 1965-1968, and some monthly interruptions in 1969, 1972, 1990, 1991. Using the National Centers for Environmental Prediction (NCEP)/National Center for Atmospheric Research (NCAR) [Kistler et al., 2001] data a spatial correlation pattern between SLP anomalies and LGB65 ice core sea-salt records was devel-

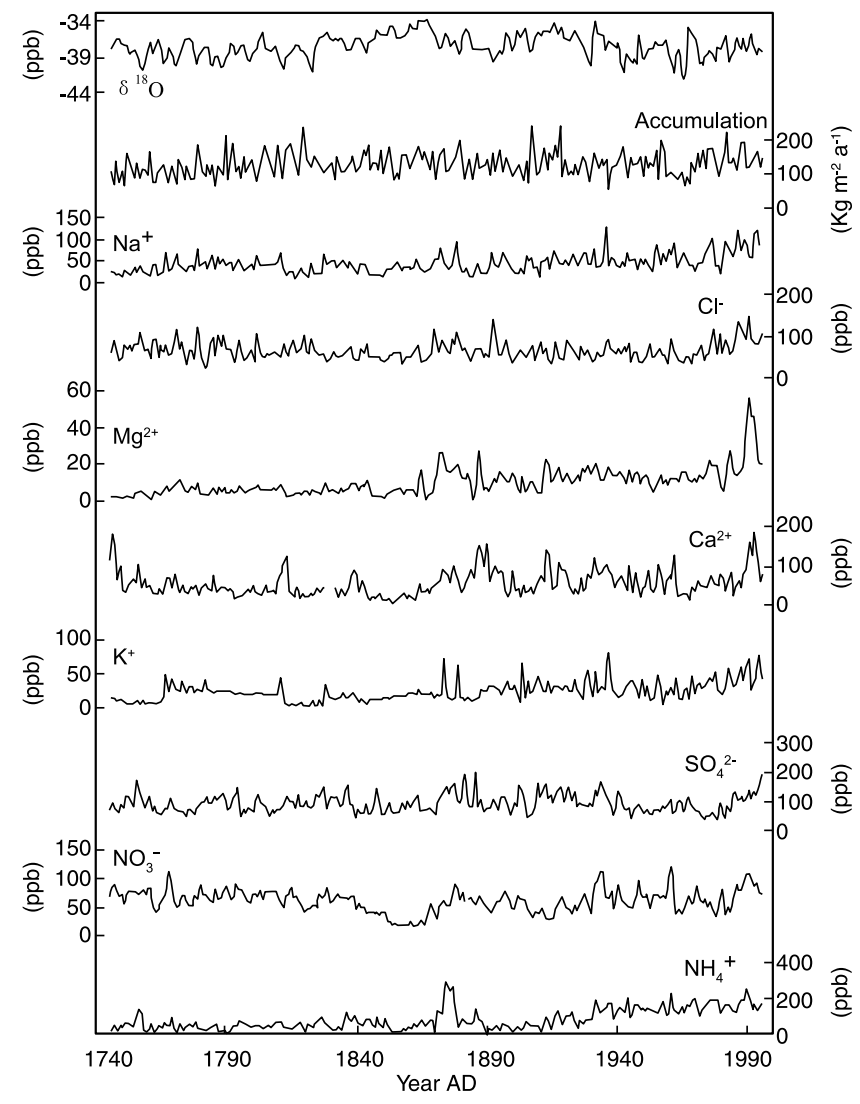

Figure 2. Glaciochemical $\left(\mathrm{Na}^{+}, \mathrm{Mg}^{2+}, \mathrm{Ca}^{2+}, \mathrm{K}^{+}, \mathrm{Cl}^{-}\right.$, $\mathrm{SO}_{4}^{2-}$, and $\mathrm{NO}_{3}^{-}$), accumulation rate, and oxygen isotope $\left({ }^{18} \mathrm{O}\right)$ annual time series from the LGB65 ice core record. 
Table 1. EOF Analysis of the Annual LGB65 Glaciochemical Time Series for the Period 1745-1996 A.D.

\begin{tabular}{|c|c|c|c|c|c|c|c|c|}
\hline Species & EOF1 & EOF2 & EOF3 & EOF4 & EOF5 & EOF6 & EOF7 & EOF8 \\
\hline \multicolumn{9}{|c|}{ Eigenvector Components } \\
\hline $\mathrm{Na}^{+}$ & 0.83 & -0.36 & 0.14 & -0.08 & 0.08 & 0.17 & -0.04 & 0.34 \\
\hline $\mathrm{NH}_{4}^{+}$ & 0.67 & -0.06 & -0.23 & 0.58 & 0.01 & -0.28 & -0.26 & -0.03 \\
\hline $\mathrm{K}^{+}$ & 0.76 & -0.34 & -0.14 & -0.14 & 0.01 & 0.45 & -0.09 & -0.25 \\
\hline $\mathrm{Mg}^{2+}$ & 0.84 & -0.11 & -0.12 & 0.05 & -0.15 & -0.22 & 0.44 & -0.05 \\
\hline $\mathrm{Ca}^{2+}$ & 0.51 & 0.42 & -0.37 & -0.55 & -0.23 & -0.22 & -0.16 & 0.03 \\
\hline $\mathrm{Cl}^{-}$ & 0.53 & 0.06 & 0.75 & -0.18 & 0.16 & -0.27 & -0.08 & -0.12 \\
\hline $\mathrm{NO}_{3}^{-}$ & 0.36 & 0.64 & -0.15 & 0.05 & 0.64 & 0.13 & 0.08 & 0.01 \\
\hline $\mathrm{SO}_{4}^{2-}$ & 0.34 & 0.66 & 0.28 & 0.26 & -0.46 & 0.30 & 0.01 & 0.03 \\
\hline \multicolumn{9}{|c|}{ Percent Variance Explained } \\
\hline $\mathrm{Na}^{+}$ & 69.21 & 13.16 & 1.98 & 0.68 & 0.57 & 2.80 & 0.19 & 11.40 \\
\hline $\mathrm{NH}_{4}^{+}$ & 45.39 & 0.39 & 5.45 & 34.12 & 0.01 & 7.92 & 6.64 & 0.09 \\
\hline $\mathrm{K}^{+}$ & 57.17 & 11.74 & 2.00 & 1.96 & 0.02 & 20.31 & 0.78 & 6.02 \\
\hline $\mathrm{Mg}^{2+}$ & 70.20 & 1.30 & 1.51 & 0.29 & 2.22 & 4.95 & 19.31 & 0.24 \\
\hline $\mathrm{Ca}^{2+}$ & 25.54 & 17.89 & 13.99 & 29.78 & 5.33 & 4.78 & 2.61 & 0.09 \\
\hline $\mathrm{Cl}^{-}$ & 28.31 & 0.35 & 56.37 & 3.24 & 2.48 & 7.12 & 0.71 & 1.42 \\
\hline $\mathrm{NO}_{3}^{-}$ & 13.23 & 40.76 & 2.34 & 0.28 & 41.00 & 1.66 & 0.71 & 0.02 \\
\hline $\mathrm{SO}_{4}^{2-}$ & 11.31 & 43.13 & 7.99 & 6.87 & 21.51 & 9.12 & 0.01 & 0.07 \\
\hline \multicolumn{9}{|c|}{ Percent of Total Variance Explained } \\
\hline & 40.0 & 16.1 & 11.5 & 9.7 & 9.1 & 7.3 & 3.9 & 2.4 \\
\hline
\end{tabular}

oped for the period 1968-1996. Because few Antarctic observations are used by NCEP/NCAR reanalysis until about 1968, and the quality of the pressure field for the reanalysis appears poor in high southern latitudes prior to then [Hines et al., 2000]. In order to further identify the representativeness of the LGB65 glaciochemical records for large-scale features of $\mathrm{SH}$ circulation, we investigated the relationship of our data with the transpolar index (TPI) [Pittock, 1980]. TPI series for 1903-1993 are based on the air pressure data at Grytviken, Orcadas, Signy Island and Orkneys, South America-Antarctic peninsula, as well as Wellington, Hokitika, Christchurch, Dunedin and Chatham Island, New Zealand. For longer timescales, a proxy of the summer transpolar index (STPI, 1745-1983) was used that was developed from sub-Antarctic tree ring records [Villalba et al., 1997].

\section{Empirical Orthogonal Function (EOF) Analysis}

[8] Empirical orthogonal function (EOF) analysis of the annually resolved glaciochemical time series is used to identify relationships with climatic variables. In the earth sciences it has become common to refer to the time series of components as the EOFs. The eigenvectors that determine the components and the variances of the series they are derived from are the eigenvectors of the correlation matrix. The eigenvectors determine the new orthogonal components which, when used to represent the multivariate date, provide the decomposition of the time series into uncorrelated components which, sequentially, represent the maximum amount of residual variance. This technique has been used for many paleoclimatic studies [Peixoto and Oort, 1992; Meeker et al., 1995; Kreutz et al., 2000; Souney et al., 2002]. Our results of EOF analysis on LGB65 major ion records for the period 1745-1996 A.D. are shown in Table 1. The first EOF (EOF1) explains a considerable $(40 \%)$ portion of the overall variance in the multivariate ice core record and is loa imarily $(>69 \%)$ by the major components of sea-salt aerosols (e.g., $\mathrm{Na}^{+}, \mathrm{Mg}^{2+}$ ). Components of an EOF that explain a significant portion of the overall variance in a multivariate data set are likely to represent some underlying physical linkages among the variants [Peixoto and Oort, 1992]. Given the location of LGB65, it is expected to mainly be affected by marine air masses [Bromwich, 1988], therefore we interpret EOF1 to be a record of marine aerosol deposition to LGB65.

\section{SLP/Sea-Salt Spatial Correlation Pattern}

[9] Numerical analyses play an important role in a variety of atmospheric studies in the high southern latitudes [Trenberth and Solomon, 1994; Bromwich et al., 1995; Simmonds and Keay, 2000]. Variations in SLP and geopotential anomalies for the SH, including Antarctica and vicinity, were examined by van Loon and Shea [1987] and Karoly [1989] and found to be the major mechanism of climate change over certain Antarctic regions [e.g., Cullather et al., 1996; Kreutz et al., 2000]. The NCEP/ NCAR reanalysis for 1948 to present [Kalnay et al., 1996; Kistler et al., 2001] is a potentially useful tool offering a reasonable picture of the Southern Hemispheric circulation, especially prior to the satellite era. However, some shortcomings of NCEP/NCAR reanalysis over the Southern Ocean have been found [Hines et al., 2000; Sturaro, 2003]. Several important developments have occurred since the production of the original NCEP/NCAR reanalysis. A very recent development is the performance of the NCEP/ Department of Energy (DOE) Atmospheric Modelling Intercomparison Project 2 (AMIP-2) reanalysis, so-called NCEP/DOE AMIP-2, which will eventually cover the years 1979-1997 [Kanamitsu et al., 2002], but SLP has not been included in this development. Nevertheless, short-term interannual variations are reasonably well captured in NCEP/NCAR starting about 1968. Thus the reanalysis from 1968 to present should be acceptable for studies of climate variability in high southern latitudes, provided that the longterm trend is properly accounted for. The usefulness of 


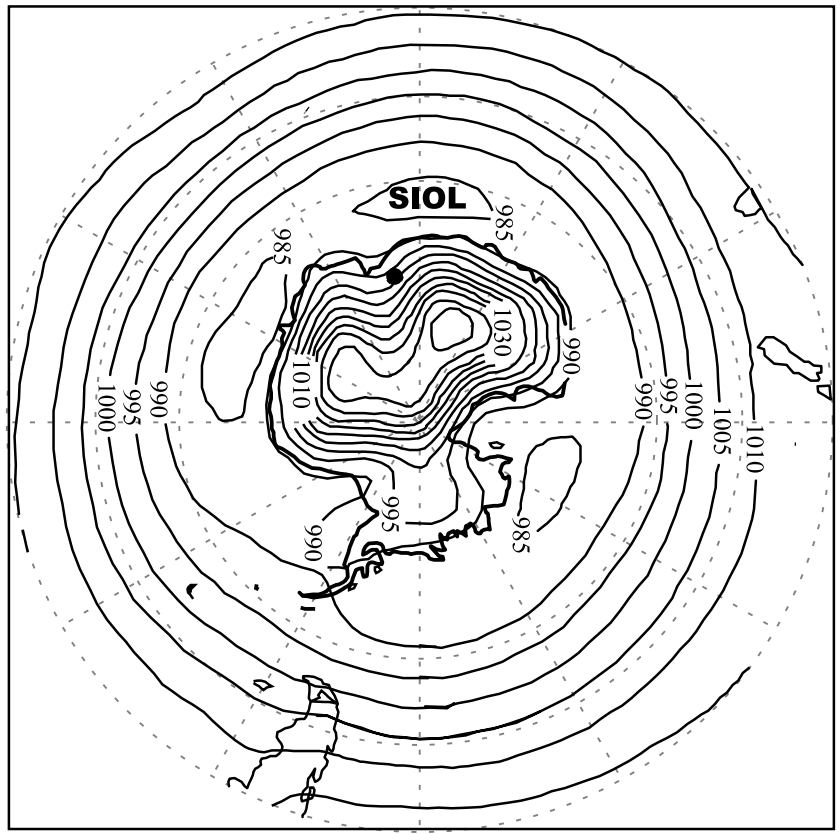

Figure 3. Climatological MSLP distribution derived from the NCEP/NCAR reanalysis (1968-1996). SIOL refers to the southern Indian Ocean low, a quasi-stationary climatological feature located north of Brydz Bay. The black dot denotes the location of the LGB65 ice core.

NCEP/NCAR-derived MSLP field in the data-sparse South Pacific and Australia-New Zealand sector of Southern Ocean, especially after 1968, is verified by recent studies [Hines et al., 2000; Marshall and Harangozo, 2000; Simmonds and Keay, 2000].

[10] Figure 3 shows the spatial pattern of the 1968-1996 SLP mean structure over the southern oceans using NCEP/ NCAR reanalysis. Three notable quasi-stationary atmospheric systems (features) are located respectively in the SIO, South Pacific Ocean and South Atlantic Ocean (Figure 3). Carleton [1989] notes that the belt of westerlies in the high-latitude $\mathrm{SH}$ includes traveling wave cyclones, which originate in the lower middle latitudes, move poleward and intensify, and then stagnate along the coast of Antarctica in four general locations (Amundsen Sea, Weddell Sea, southeast and southwest Indian Ocean). There are significant levels of cyclogenesis in the very baroclinic region between the continent and the sea ice, and between the marginal ice zone and the open ocean [Turner et al., 1998; Simmonds and Keay, 2000]. These wave cyclones carry heat and moisture poleward, contributing to $\mathrm{SH}$ heat redistribution. Climatological charts of monthly MSLP resolve four quasi-stationary lows that are always characterized by lower than $988 \mathrm{hPa}$. These features have been shown to influence or govern climate change over, using ice core calibrated climate proxy series from, Siple Dome in west Antarctica [Kreutz et al., 2000], Dronning Maud Land [Isaksson et al., 1996] and Law Dome [Morgan et al., 1991; Souney et al., 2002] in east Antarctica. The relationship between climate change over PEL and these features, specifically the closest, the southern Indian Ocean low (hereinafter SIOL) is $\mathrm{p}$ ed here. Climatological charts of monthly mean SLP generally resolve this SIOL as extending from $70^{\circ} \mathrm{E}$ to $120^{\circ} \mathrm{E}$ longitudes in the circumpolar trough [Schwerdtfeger, 1984; King and Turner, 1997; Bromwich and Parish, 1998]. Recent studies show that the interannual SLP variability in SIOL is relatively modest [e.g., Simmonds and Murray, 1999] whereas, by contrast, large variability and shifts are apparent in the Amundsen and Bellingshausen Seas low [e.g., Cullather et al., 1996].

[11] Using NCEP software of Linear Correlations in Atmospheric Seasonal/Monthly Averages (available online at http://www.cdc.noaa.gov/correlation/), spatial patterns of correlation between annually averaged SLP and LGB65 annual values of EOF1 (Figure 4a) and sodium (Figure 4d) records are shown. There are strong negative correlations between the SIOL and annual sea-salt concentrations in LGB65 ice core (SLP/EOF1: $r=-0.6, p<0.05$, degree of freedom (df) is 27; SLP/Na: $r=-0.5, p<0.01$, df $=27$ ).

[12] In order to reveal the seasonal representatives of sea salt to SLP in the SIO, we investigate the correlations of LGB65 EOF1 and sodium with summer (October to March) and winter (April to September) SLP, respectively. Both summer (Figures $4 \mathrm{~b}$ and $4 \mathrm{e}$ ) and winter (Figures $4 \mathrm{c}$ and $4 \mathrm{f}$ ) correlations are significant at confidence levels better than $95 \%$, but the spatial correlation patterns for winter are closer than for summer to the annually averaged patterns. Strong correlation occurs over the domain $55^{\circ} \mathrm{S} \sim 65^{\circ} \mathrm{S}$, $60^{\circ} \mathrm{E} \sim 90^{\circ} \mathrm{E}$ both for annual and winter patterns, with the maximum correlated area (latitude), around $60^{\circ} \mathrm{S}$, which is coincident with the recent finding that the greatest cyclogenetic density occurs at very high latitudes, with the axis of the maximum lying on, or to the south of, $60^{\circ} \mathrm{S}$ [Simmonds and Keay, 2000]. The domain for the summer pattern $(60-$ $70^{\circ} \mathrm{S}, 60-90^{\circ} \mathrm{E}$ ) shows a diminution and lies southward. This is probably attributable to the seasonal changes of sea ice extent and thus the intensities of cyclogenesis [Simmonds and Keay, 2000].

[13] The robust correlations in our study suggest strong meridional sea-salt aerosol transport from SIOL to LGB65, PEL. Marine air intrusion into east Antarctica is related to large-scale disturbances over the ocean or blocking anticyclones [Naithani et al., 2002]. Lejenas [1984] found, for the $500 \mathrm{hPa}$ field, that the ocean sector between Australia and New Zealand is the preferred region for blocking anticyclones. Pook and Cowled [1999] demonstrated that vortices originating over the Southern Ocean can penetrate the high plateau of east Antarctica and move well inland before decaying. They report that the development of an intense blocking anticyclone in the Tasman Sea sector appears to be critical for the penetration of such depressions inland. Collection of future ice cores south to LGB65 by Chinese ITASE may reveal how far to inland the SIOL influence goes.

\section{Correlation With Meteorological Records in the Southern Indian Ocean}

[14] Kerguelen Island and New Amsterdam Island are two of the few meteorological stations available in the region of the SIO. We compare the temperature records at two stations with the LGB65 $\delta^{18} \mathrm{O}$ series, and the SLP records from these stations with the LGB65 sodium and EOF1 series. 

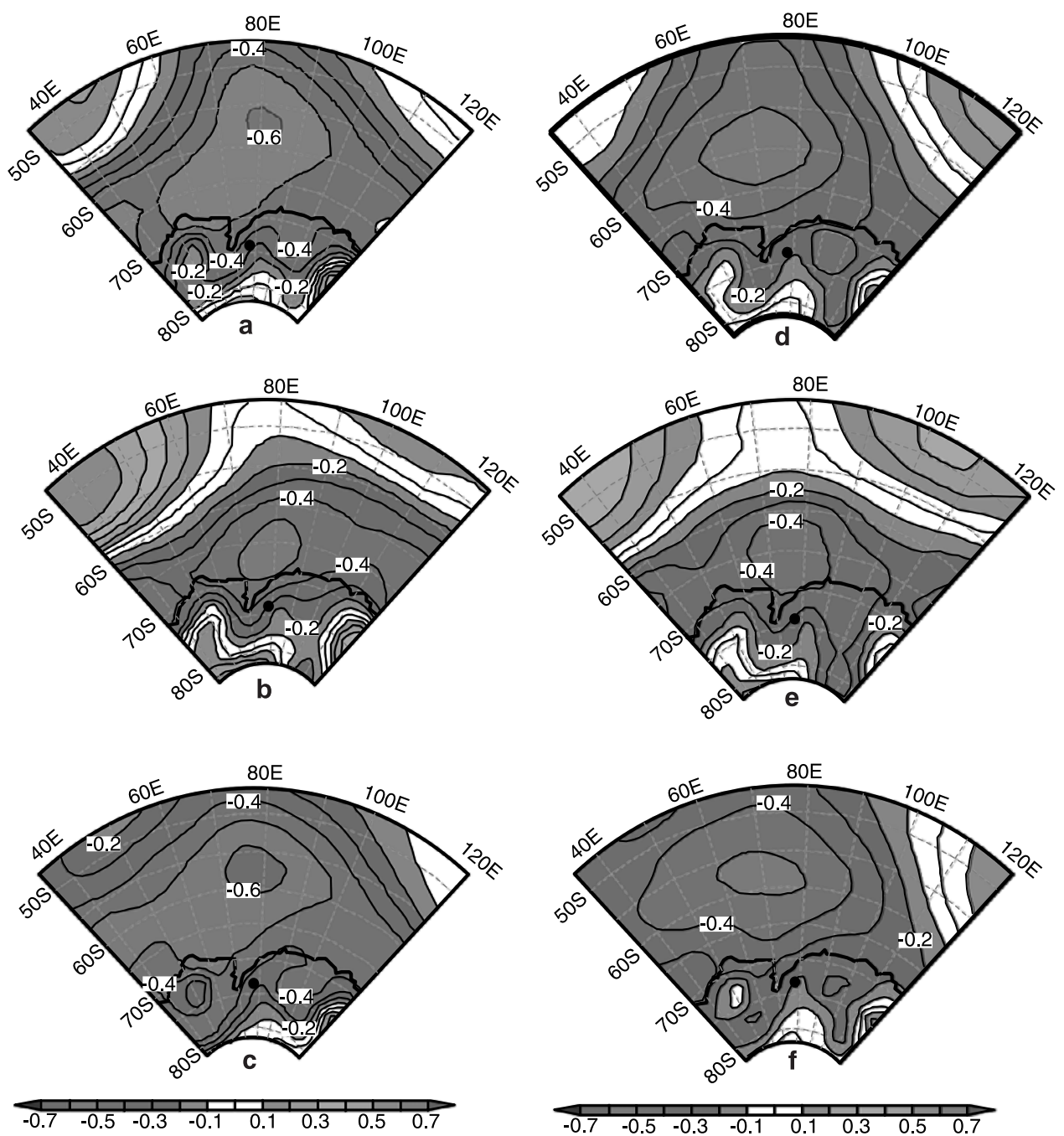

Figure 4. $(\mathrm{a}-\mathrm{c})$ Spatial correlation patterns from the NCEP/NCAR reanalyses between LGB65 EOF1 and SLP in the annual, summer (October to March) and winter (April to September) basis, respectively, for the period 1968-1996; (d-f) same as Figures 4a-4c but for LGB65 sodium. The black dot represents the location of LGB65. See color version of this figure at back of this issue.

[15] Positive correlations exist between the Kerguelen/ New Amsterdam temperature and $\delta^{18} \mathrm{O}$ series (not shown). Although $\delta^{18} \mathrm{O}$ primarily reflects temperature at the precipitating site there is a close linkage between precipitation $\delta^{18} \mathrm{O}$ and the source area temperature [Noone and Simmonds, 2002; Bradley et al., 2003; Masson-Delmotte et al., 2003]. However, there are small phase differences between $\delta^{18} \mathrm{O}$ and the air temperatures of the two stations, that may due to the effect of the latitudinal displacement from source regions during moisture transport [Bromwich and Weaver, 1983], as well as the postdepositional processes of snowfall. The multidecadal warming trend in sea surface temperature observed since the 1970s in the SIO region [Smith et al., 1994; Aoki et al., 2003] is also evident in the LGB65 $\delta^{18} \mathrm{O}$ record.

[16] The extreme years of sodium concentrations at LGB65 and station SLPs at Kerguelen, New Amsterdam and Davis, defined as the values exceeding 1 standard deviation $(1 \sigma)$, are listed in Table 2. Although the correspondence betwee

B65 sodium peaks (troughs) and SLP troughs (peaks) are not one to one, the same extreme years appear in the LGB65 sodium and Kerguelen SLP series, although fewer similar years exist between LGB65 sodium and New Amsterdam SLP. The dissimilarity of extreme years between LGB65 sodium and Davis SLP, in contrast with that at Kerguelen and New Amsterdam islands, may in part be due to interruptions in Davis SLP records. We also examine the relationships between LGB65 sea-salt records and air pressure records at coastal stations such as Mirny, Mawson and Casey (these follow a generally similar trend), however these records have too many interruptions to allow significant correlations.

[17] Sodium and EOF1 series exhibit strong negative correlations with SLP variations at Kerguelen Island (SLP/Na: $r=-0.48, p=0.002, d f=35 ;$ SLP/EOF1: $r=-0.44, p=0.003, d f=35$. Note that in general EOF1 is superior or equals $\mathrm{Na}$ as a SLP indicator, as shown in Figure 4), and is weaker at New Amsterdam Island, probably due to its lower latitudinal location. Although 
Table 2. Comparison of High Extreme Years $(>1 \sigma)$ of LGB65 Sodium With Low Extreme Air Pressure Years at Stations of Kerguelen Island (KI, 1952-1988), New Amsterdam Island (NAI, 1951-1988), and Davis (1958-1991), as Well as the Comparison Between Low Extreme Years of LGB65 Sodium and High Air Pressure Years at These Stations

\begin{tabular}{llll}
\hline \hline High Na & KI, Low SLP & NAI, Low SLP & Davis, Low SLP \\
\hline 1956,1957 & 1956,1957 & $1956,1957,1959$ & 1960 \\
1963 & 1963 & 1963 & - \\
1966,1967 & 1966,1967 & 1966,1967 & - \\
1976,1977 & 1976,1977 & 1977,1978 & 1979 \\
1983,1984 & 1983,1984 & 1983,1984 & - \\
1988 & 1988 & 1988 & 1989 \\
\hline Low Na & KI, High SLP & NAI, High SLP & Davis, High SLP \\
1954,1955 & 1954,1955 & 1955 & - \\
1958,1959 & 1958,1959 & 1958 & 1959 \\
1964,1965 & 1964,1965 & 1964,1965 & - \\
1971 & 1971 & 1971 & 1971,1972 \\
1981,1982 & 1981,1982 & 1981,1982 & 1980 \\
1986 & 1986 & 1986 & - \\
\hline \hline
\end{tabular}

the station results are not quantitatively consistent with the NCEP/NCAR reanalysis, probably due to the different timescale and/or the shortcomings of the latter, the overall pattern supports results presented earlier using the NCEP/ NCAR reanalysis, suggesting that strong teleconnections exist between the SIO and PEL, and that the SIOL plays an important role in influencing climate change in PEL. Thus long-term sea-salt records can be used as a valuable proxy for climate change over SIO, and can contribute to the understanding of intrahemispheric cold air mesocyclones in the Australasian sector, because the SIOL is believed to be a critical region for mesocyclogenesis in the Australasian sector [Carleton and Song, 1997].

\section{The 250-Year Glaciochemical Sea-Salt Proxy of SLP Variability: Correlation With Large-Scale Atmospheric Circulation}

[18] Although our results suggest a strong relationship between LGB65 EOF1 and SIOL, we acknowledge that 48 years of correlation is insufficient to establish the LGB65 record as an absolutely robust proxy of the SIOL prior to 1948. Given our goal of estimating climatic variability in the SIO region over the past 250 years using the EOF1 and sea-salt time series, we now seek to extend the EOF1 (and sodium)/instrumental correlation prior to the 48 years represented by NCEP/NCAR data. Differences in SLP between pairs of stations have traditionally been used as indices of large-scale atmospheric circulation [Lamb, 1977]. The transpolar index (TPI), defined as the difference in sea level pressure between Hobart, Tasmania and Stanley, South Atlantic Ocean, was proposed by Pittock [1980] to measure the center of the polar vortex moving toward one of these two points. Later, Karoly et al. [1996] and Simmonds [2003] described the dominant modes of interannual atmospheric circulation. They found that the second principal component of the low-pass filtered MSLP is well correlated with the TPI. The TPI is a zonally asymmetric mode of wave number 1 , that is represented by an oscillation in pressure/height between Australian and South American sectors. Hence it may be associated with long term variability of $\mathrm{SH}$ circulation.
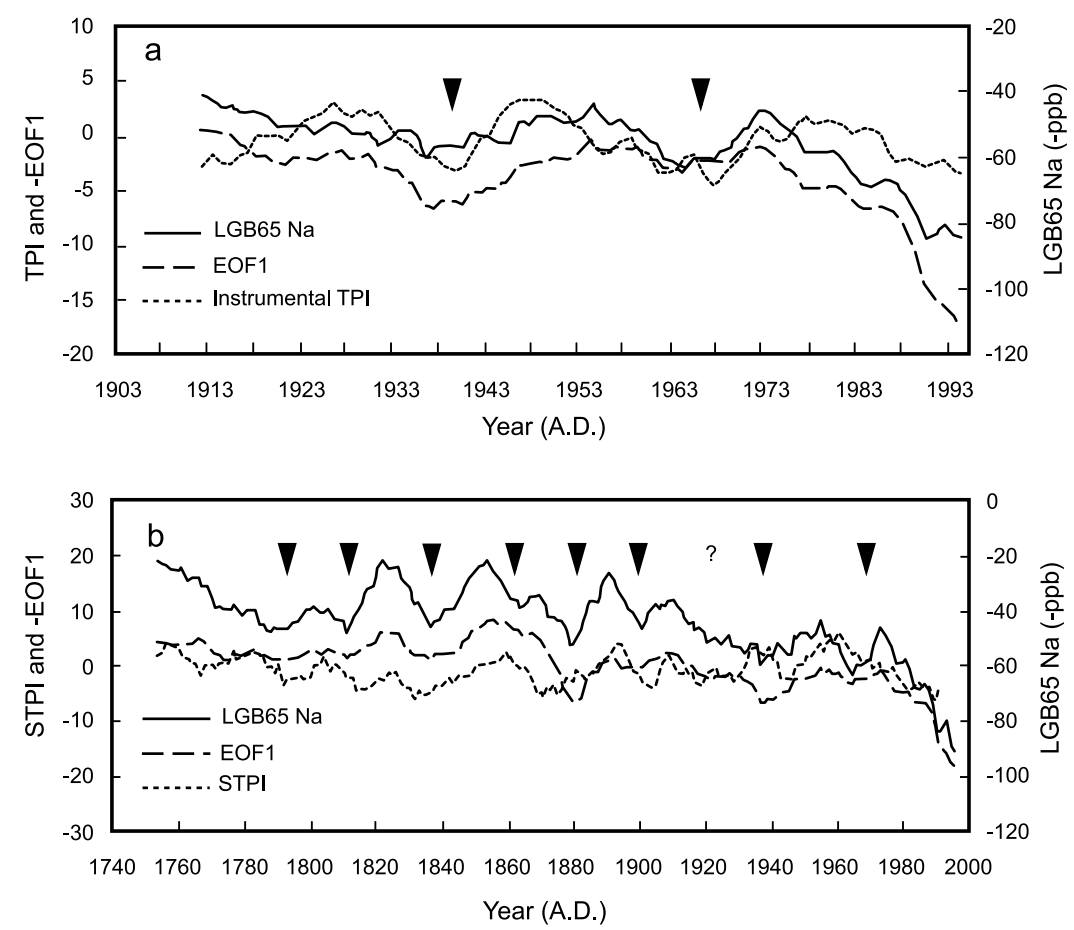

Figure 5. (a) LGB65 sodium record shown with instrumentally reconstructed transpolar index (TPI) (for method, see Villalba et al. [1997]), (b) correlation of the STPI series inferred from sub-Antarctic tree rings [Villalba et al., 1997] with 252-year sodium records (reversed here), and (c) EOF1 series (reversed here) of LGB65. All lines represent 10-year smoothed variations. Triangles point to the high Na (EOF1), and therefore $1 \quad$ versal $\mathrm{Na}(\mathrm{EOF} 1)$ values. 
21.1 years

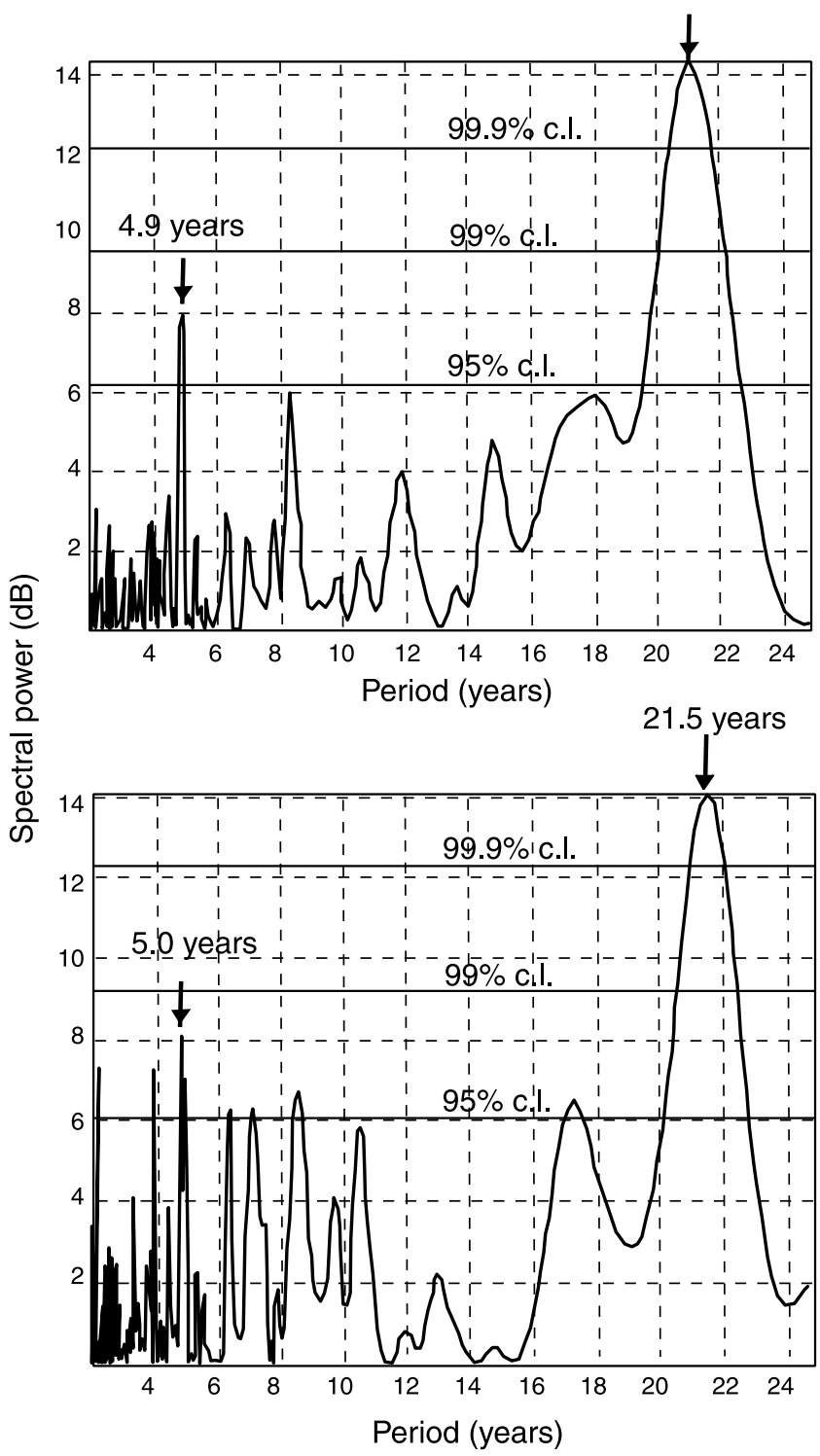

Figure 6. Power spectra of LGB65 (top) sodium and (bottom) EOF1 record for the period 1745-1996 A.D. The $95 \%, 99 \%$, and $99.9 \%$ confidence levels are based on a first-order Markov model [Meeker et al., 1995]. Period represents years per cycle.

[19] A TPI based on instrumental SLP data can only be extended back to the early 1900s. The longest STPI record, 1746-1984 A. D., was reconstructed by Villalba et al. [1997], using a tree ring chronology network developed from a sub-Antarctic forest. A similar method was used for reconstructing the Arctic Oscillation [D'Arrigo et al., 2003] and the Antarctic Oscillation [Jones and Widmann, 2003] using tree ring records. For the STPI data set, 21 tree ring width chronologies (using two species Nothofagus pumilio and $N$. betuloides) were developed from Tierra del Fuego $\left(53-55^{\circ} \mathrm{S}\right.$, South America), the southernmost area of forested land in the world. Also, five tree ring chronologies (three for Halocarpus and two for Lagarostrobus) were derived from New Zealand. The premise ern South American and New Zealand tree rings for predicting MSLP on opposite sides of the Antarctic was based on the strong teleconnection between these two regions as revealed by the spatial correlation patterns of MSLP [Villalba et al., 1997, Figures 3 and 4]. We use this data because the SIOL is located roughly over the Australian sector of the Southern Ocean, one end of the STPI. Positive STPI values suggest intensification of SLP over the west Antarctic sector (e.g., Amundsen Sea Low) [Kreutz et al., 2000] and formation of a positive pressure anomaly over Australian-New Zealand sector, while negative STPI values reflect opposite conditions.

[20] TPI series for winter (or annual), the season showing major SLP variability, would be the most ideal proxy for this study, yet up to today the STPI based on tree ring records is the only preinstrumental TPI proxy available for this purpose. Fortunately the summer SLP changes in SIO, based on Figure 4, represent LGB65 Na (EOF1) variations, therefore, STPI can be used for this comparison. In Figure 5a, the 10-year smoothed variations of sodium records (we plot reversed $\mathrm{Na}$ and EOF1 in the figures so that the correlations are visibly stronger) are plotted with that of the TPI constructed from atmospheric pressure observations (MSLP) using stations from two opposing regions, i.e., South American-Antarctic Peninsula stations and New Zealand stations (for method, see Villalba et al. [1997]). As both higher EOF1 (sodium) and lower TPI indicate a deeper SIOL, cross-spectrum analysis suggests that, for the periodicity 21-24 years, the two series are consistent (coherence is 0.62 for TPI/EOF1, and 0.54 for TPI/-Na) in showing MSLP variation over SIO. This suggests that the sea salt transported to PEL is strongly linked to large-scale circulation at high southern latitudes. To verify this, we extend this comparison to the 250-year record (Figures $5 \mathrm{~b}$ and $5 \mathrm{c}$ ). Again, cross-spectrum analysis is applied to investigate the relationship between 10-year smoothed STPI and LGB65 EOF1 (sodium) variations. The results suggest a strong coherence $(0.68$ for STPI/-EOF1, and 0.60 for STPI/-Na) at the periodicity 20-22 years, with STPI leading by approximately 1.5 years relative to LGB65 EOF1 (Na). This emphasizes the observation that the TPI shows evidence of decadal-scale variations [Carleton, 2003].

[21] The coherency of STPI with sea-salt records in PEL implies that the change of MSLP over the SIOL is not only a mesoscale phenomenon, but is also involved in large-scale SH circulation. Positive (negative) values of TPI, therefore trough (peak) values of sea salt (EOF1), accompany an enhanced ridge (trough) in the Australasian region and enhanced trough (ridge) in the South America sector, and vice versa. The fluctuation of this pattern reflects shifting of the Antarctic polar vortex toward two opposite ends, i.e., Australasian and South American.

[22] The downward trends of LGB65 Na (EOF1) after 1980s are not evidenced in STPI, possibly due to a longer term variations, that we do not yet understand.

[23] Past study of the relationship between the TPI and the Southern oscillation index (SOI) [Pittock, 1984; Carleton, 1989, 2003] suggests that, for the middle decades of the 20th century, there is a significant positive association when the former leads the latter by up to 

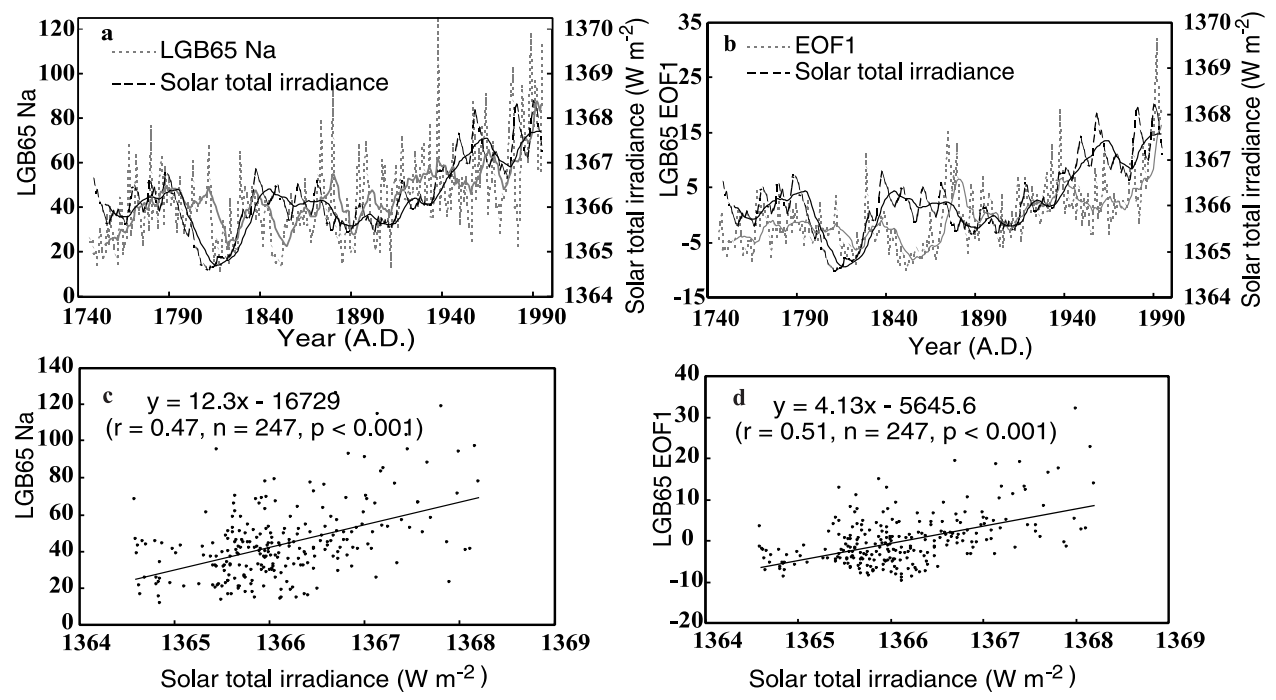

Figure 7. Relationship between variations of LGB65 (a) sodium and (b) EOF1 solar total irradiance [Lean et al., 1995], dense lines represent 10-point smoothed profiles, (c) and (d) are the linear correlations of the two data sets in Figures $7 \mathrm{a}$ and $7 \mathrm{~b}$, respectively.

1 year. However, they found that the temporal stability of the SOI-TPI association is questionable. No significant correlations between LGB65 sea-salt variations and SOI are detected in this study, either.

\section{Periodic Structure of 250-Year SLP Variability for Southern Indian Ocean}

[24] Using spectral analysis [Meeker et al., 1995], we investigate the dominant periodicities in the annual LGB65 sea-salt record. The $95 \%, 99 \%$ and $99.9 \%$ red noise critical values were estimated from fifteen simulation runs of Markov process with annual LGB65 EOF1 (Figure 6a) and sodium (Figure 6b) time series, respectively. A peak that exceeds the $99.9 \%$ confidence level is found at $\sim 21$ years. This periodicity is also exhibited clearly in Figure 5. Deepening of the SIOL occurs around 1790, $1810,1838,1860,1880,1900,1940$ A.D., and continuously after the 1970s. Episodes of weakening SIOL occur approximately $1750,1795,1825,1850,1870,1890,1910$, and 1955 A.D. Both deepenings and weakenings exhibit an approximately 20 - to 30 -year periodicity, except a missing trough around 1920 and two peaks around 1770 and 1930. The results of our spectral analysis agree with the findings of Law Dome sea-salt record [Souney et al., 2002], and also with the 20- to 30-year oscillation of instrumental SLP between $40^{\circ} \mathrm{S}$ and $50^{\circ} \mathrm{S}$ identified by Enomoto [1991]. This supports the use of sea-salt records from PEL as a proxy for MSLP over the SIO, and probably for the shifting of the polar vortex as well. We also notice a secondary peak that exceed $95 \%$ confidence level at $\sim 5$ years. Interestingly, the Antarctic Circumpolar Wave (ACW) has a wave number of 2 and takes $\sim 8-10$ years to circle Antarctica, leading to a periodicity of 4-5 years at any location [White and Peterson, 1996; Connolley, 2003]). This secondary periodicity may be a signature of the ACW, and possibly ENSO.

[25] Because the 21-year periodicity is close to solar Hale cycle, we investigate whether solar forcing might be responsible for the dec known that the magnetic polarities proceeding and following sunspots in each hemisphere, as well as the polarity of the poles, reverse from one activity cycle of 11 years to the next. Thus the magnetic activity exhibits a 22-year repeatability, known as the Hale cycle. We use the annual solar irradiance database (for the period 1745-1994) developed by Lean et al. [1995] (data available at http:// www.ngdc.noaa.gov/paleo/forcing.html) based on parameterizations of sunspot darkening and facular brightening from the sunspot record that extends back to 1610 A.D. Figure 7 shows the correlation of solar total irradiance with LGB65 sea-salt records. The 10-year smoothed profiles exhibit similar features between them. Results reveal a high linear correlation (irradiance/ $\mathrm{Na}: \mathrm{r}=0.47, \mathrm{p}<0.001$; irradiance/EOF1: $\mathrm{r}=0.51, \mathrm{p}<0.001)$. This suggests that solar activity may be one of the major forcing factors for the decadal-scale SLP variations over the southern oceans.

[26] There is some evidence [Craig and Willett, 1951] that long-term variations in global pressure patterns are more closely associated with the Hale double sunspot than with the 11-year cycle. Early statistic study [Shaw, 1928] based on correlation between sunspot number and surface atmospheric pressure found that above $40^{\circ}$ latitude in both hemispheres the pressure is less at sunspot maxima than at sunspot minima, implying that low-pressure troughs can develop more often in years of high solar activity. Taking as an evidence, the Dalton Minimum ( AD 1820), a less clear minimum than other major minimums (all beyond the LGB65 records period), is well reflected by the low values of LGB65 Na (EOF1). The actual process through which this forcing could be enacted is beyond the scope of this study.

\section{Conclusions}

[27] EOF analysis of the annual LGB65 glaciochemical time series indicates that EOF1 is a record of marine aerosol deposition to PEL, east Antarctica. Comparison of meteorological observations from Kerguelen and New Amsterdam 
islands with the sea-salt proxies in the LGB65 ice core, as well as the NCEP/NCAR reanalysis SLP data, suggest that sea-salt aerosol input to PEL is strongly linked to variations of a quasi-stationary low in the high latitudes of the SIO. Comparison of our data with the STPI indicates that SIOL variability may be an indicator of the behavior of the polar vortex. As such, the results presented here provide a 250-year record of variations of the SIOL and, indirectly, the polar vortex, and these exhibit an approximately 21-year periodicity possibly related to the solar Hale cycle.

[28] Acknowledgments. We thank R. Villalba now at the Department de Dendrocronologia e Historia Ambientol, Argentina, for providing the STPI data, J. M. Souney for fruitful discussion, and Lu Longhua and Wu Bingyi for statistical analysis. Three anonymous reviewers are greatly appreciated. Members of the Chinese ITASE traverses contributed greatly to the success of this project. This work is supported by the National Natural Science Foundation of China (40305007), the Ministry of Science and Technology of China (2001CB711003), and the Chinese Academy of Sciences (KZCX2-303)

\section{References}

Aoki, S., M. Yoritaka, and A. Masuyama (2003), Multidecadal warming of subsurface temperature in the Indian sector of the Southern Ocean, J. Geophys. Res., 108(C4), 8081, doi:10.1029/2000JC000307.

Bradley, R. S., M. Vuille, D. Hardly, and L. G. Thompson (2003), Low latitude ice cores record Pacific sea surface temperature, Geophys. Res. Lett., 30(4), 1174, doi:10.1029/2002GL016546.

Bromwich, D. H. (1988), Snowfall in high southern latitudes, Rev. Geophys., 26(1), 149-168.

Bromwich, D. H., and T. R. Parish (1998), Meteorology of the Antarctic, in Meteorology of the Southern Hemisphere, edited by D. J. Karoly and D. G. Vincent, pp. 175-200, Am. Meteorol. Soc., Boston, Mass.

Bromwich, D. H., and C. J. Weaver (1983), Latitudinal displacement from main moisture source controls $\delta^{18} \mathrm{O}$ of snow in coastal Antarctica, Nature, 301, 145-147.

Bromwich, D. H., F. M. Robasky, R. I. Cullather, and M. L. van Woert (1995), The atmospheric hydrologic cycle over the Southern Ocean and Antarctica from operational numerical analyses, Mon. Weather Rev., 123, 3518-3538.

Carleton, A. M. (1989), Antarctic sea ice relationships with indices of the atmospheric circulation of the Southern Hemisphere, Clim. Dyn., 3, $207-$ 220.

Carleton, A. M. (2003), Atmospheric teleconnections involving the Southern Ocean, J. Geophys. Res., 108(C4), 8080, doi:10.1029/2000JC000379.

Carleton, A. M., and Y. Song (1997), Synoptic climatology, and intrahemispheric associations, of cold air mesocyclones in the Australasian sector, J. Geophys. Res., 102(D12), 13,873-13,887.

Connolley, W. M. (2003), Long-term variation of the Antarctic Circumpolar Wave, J. Geophys. Res., 108(C4), 8076, doi:10.1029/2000JC000380.

Craig, R. A., and H. C. Willett (1951), Solar energy variations as a possible cause of anomalous weather change, in Compendium of Meteorology, 379 pp., Am. Meteorol. Soc., Boston, Mass.

Cullather, R. I., D. H. Bromwich, and M. L. van Woert (1996), Interannual variations in Antarctic precipitation related to El Nino-Southern Oscillation, J. Geophys. Res., 101(D14), 19,109-19,118.

Curran, M. A. J., and A. S. Palmer (2001), Suppressed ion chromatography methods for the routine determination of ultra low level anions and cations in ice cores, J. Chromatogr. A, 919, 107-113.

D'Arrigo, R. D., E. R. Cook, M. E. Mann, and G. C. Jacoby (2003), Tree-ring reconstructions of temperature and sea-level pressure variability associated with the warm-season Arctic Oscillation since AD 1650, Geophys. Res. Lett., 30(11), 1549, doi:10.1029/2003GL017250.

Enomoto, H. (1991), Fluctuations of snow accumulation in the Antarctic and sea level pressure in the Southern Hemisphere in the last 100 years, Clim. Change, 18, 67-87.

Hines, K. M., D. H. Bromwich, and G. J. Marshall (2000), Artificial surface pressure trends in the NCEP-NCAR reanalysis over the Southern Ocean and Antarctica, J. Clim., 13, 3940-3952.

Isaksson, E., W. Karlén, N. Gunderstrup, P. Mayewski, S. Whitlow, and M. Twickler (1996), A century of accumulation and temperature changes in Dronning Maud Land, Antarctica, J. Geophys. Res., 101(D3), $7085-$ 7094.

Jones, J. M., and M. Widmann (2003), Instrumental and tree-ring-based estimates of the Antarctic O ill ion, J. Clim., 16, 3511-3524.
Kalnay, E., et al. (1996), The NCEP/NCAR 40-year reanalysis project, Bull. Am. Meteorol. Soc., 77, 437-471.

Kanamitsu, M., W. Ebisuzaki, J. Woollen, S. Yang, J. J. Hnilo, M. Fiorino, and G. L. Potter (2002), NCEP-DOE AMIP-II Reanalysis (R-2), Bull. Am. Meteorol. Soc., 1631-1643.

Karoly, D. J. (1989), Southern Hemisphere circulation features associated with El Nino-Southern Oscillation events, J. Clim., 2, 1239-1252.

Karoly, D. J., P. Hope, and P. D. Jones (1996), Decadal variations of the Southern Hemisphere circulation, Int. J. Climatol., 16, 73-738.

King, J. C., and J. Turner (1997), Antarctic Meteorology and Climatology, 409 pp., Cambridge Univ. Press, New York.

Kistler, R., et al. (2001), The NCEP/NCAR 50-year reanalysis: Monthly means CD-ROM and documentation, Bull. Am. Meteorol. Soc., 82(2), $247-267$.

Kreutz, K. J., P. A. Mayewski, I. I. Pittalwala, L. D. Meeker, M. S. Twickler, and S. I. Whitlow (2000), Sea level pressure variability in the Amundsen Sea region inferred from a west Antarctic glaciochemical record, J. Geophys. Res., 105(D3), 4047-4059.

Lamb, H. H. (1977), Climate History and the Future, 345 pp., Princeton Univ. Press, Princeton, N. J.

Lean, J., J. Beer, and R. Bradley (1995), Reconstruction of solar irradiation since 1610: Implications for climate change, Geophys. Res. Lett., 22(23), 3195-3198.

Lejenas, H. (1984), The annual cycle of the eddy momentum flux caused by the planetary-scale Southern Hemisphere $500-\mathrm{mb}$ seasonally forced waves, J. Meteorol. Soc. Jpn., 62, 252-260.

Li, Z., M. Zhang, D. Qin, C. Xiao, J. Kang, and J. Li (1999), Primary research on the seasonal variations of $\delta^{18} \mathrm{O}, \mathrm{Cl}^{-}, \mathrm{NO}_{3}^{-}, \mathrm{Na}^{+}$, and $\mathrm{Ca}^{2+}$ in the snow and firn recovered from Princess Elizabeth Land, Antarctica, Chin. Sci. Bull., 44, 2270-2274.

Marshall, G. J., and S. A. Harangozo (2000), An appraisal of NCEP/NCAR reanalysis MSLP data viability for climate studies in the South Pacific, Geophys. Res. Lett., 27(19), 3057-3060.

Masson-Delmotte, V., M. Delmotte, V. Morgan, D. Etheridge, T. van Ommen, S. Tartarin, and G. Hoffmann (2003), Recent southern Indian Ocean climate variability inferred from a Law Dome ice core: New insights for the interpretation of coastal Antarctic isotopic records, Clim. Dyn., 21, 153-166.

Mayewski, P. A., and I. D. Goodwin (1999), Antarctic's role pursued in global climatic change, Eos Trans. AGU, 80(35), 398, 400.

Meeker, L. D., P. A. Mayewski, and P. Bloomfield (1995), A new approach to glaciochemical time series analysis, in Ice Core Studies of Global Biogeochem. Cycles, edited by R. J. Delmas, pp. 383-400, SpringerVerlag, New York.

Meyerson, E. A., P. A. Mayewski, K. J. Kreutz, L. D. Meeker, S. I. Whitlow, and M. S. Twickler (2002), The polar expression of ENSO and sea-ice variability as recorded in a South Pole ice core, Ann. Glaciol., $35,430-436$

Morgan, V. I., C. W. Wookey, J. Li, T. D. van Ommen, W. Skinner, and M. F. Fitzpatrick (1991), Site information and initial results from deep ice core drilling on Law Dome, Antarctica, J. Glaciol., 43, 3-10.

Mosley-Thompson, E. (1992), Paleoenvironmental conditions in Antarctic since A.D. 1500: Ice core evidence, in Climate Since A.D. 1500, edited by R. S. Bradley and P. D. Jones, pp. 572-591, Routledge, New York. Naithani, J., H. Gallée, and G. Schayes (2002), Marine air intrusion into the Adelie Land sector of east Antarctica: A study using the regional climate model (MAR), J. Geophys. Res., 107(D11), 4124, doi:10.1029/ 2000JD000274.

Noone, D., and I. Simmonds (2002), Associations between $\delta^{18} \mathrm{O}$ of water and climate parameters in a simulation of atmospheric circulation for 1979-95, J. Clim., 15, 3150-3169.

Palmer, A. S., T. D. van Ommen, M. A. J. Curren, V. Morgan, J. M. Souney, and P. A. Mayewski (2001), High-precision dating of volcanic events (A. D. 1301-1995) using ice cores from Law Dome, Antarctica, J. Geophys. Res., 106(D22), 28,089-28,095.

Peel, D. A., and R. Mulvaney (1992), Time trends in the pattern of oceanatmosphere exchange in an ice core from the Weddell Sea sector of Antarctica, Tellus, Ser. B, 44, 430-442.

Peixoto, J. P., and A. H. Oort (1992), Physics of Climate, 520 pp., Am. Inst. of Phys., College Park, Md.

Petit, J. R., et al. (1999), Climate and atmospheric history of the past 42,0000 years from the Vostok ice core, Antarctica, Nature, 399, 429436.

Pittock, A. B. (1980), Patterns of climate variation in Argentina and Chile. I: Precipitation, 1931-1960, Mon. Weather Rev., 112, 1341-1353.

Pittock, A. B. (1984), On the reality, stability, and usefulness of Southern Hemisphere teleconnections, Aust. Meteorol. Mag., 32, 75-82.

Pook, M., and L. Cowled (1999), On the detection of weather systems over Antarctic interior in the FROST analyses, Weather Forecast., 14, 920929. 
Qin, D. H., J. W. Ren, J. C. Kang, C. D. Xiao, Z. Q. Li, Y. S. Li, B. Sun, W. Z. Sun, and X. X. Wang (2000), Primary results of glaciological study along a $1100 \mathrm{~km}$ transect from Zhongshan station to Dome A, east Antarctic ice sheet, Ann. Glaciol., 31, 198-204.

Schwerdtfeger, W. (1984), Weather and Climate of the Antarctic, 435 pp., Elsevier Sci., New York.

Shaw, N. (1928), Manual of Meteorology, vol. 2, Comparative Meteorology, Univ. Press, Cambridge, UK.

Simmonds, I. (2003), Modes of atmospheric variability over the Southern Ocean, J. Geophys. Res., 108(C4), 8078, doi:10.1029/2000JC000542.

Simmonds, I., and K. Keay (2000), Mean Southern Hemisphere extratropical cyclone behavior in the 40-year NCEP-NCAR reanalysis, J. Clim., $13,873-885$.

Simmonds, I., and R. J. Murray (1999), Southern extratropical cyclone behavior in ECMWF analyses during the FROST special observing periods, Weather Forecast., 14, 878-891.

Smith, T. M., R. W. Reynolds, and C. F. Ropelewski (1994), Optimal averaging of seasonal sea surface temperatures and associated confidence intervals (1860-1989), J. Clim., 7, 949-964.

Souney, J. M., P. A. Mayewski, I. D. Goodwin, L. D. Meeker, V. Morgan, M. A. J. Curran, T. D. van Ommen, and A. S. Palmer (2002), A 700-year record of atmospheric circulation developed from the Law Dome ice core, east Antarctica, J. Geophys. Res., 107(D22), 4608, doi:10.1029/ 2002JD002104.

Stenni, B., M. Proposito, R. Gragnani, O. Flora, J. Jouzel, S. Falourd, and M. Frezzotti (2002), Eight centuries of volcanic signal and climate change at Talos Dome (east Antarctica), J. Geophys. Res., 107(D9), 4076, doi:10.1029/2000JD000317.

Sturaro, G. (2003), A closer look at the climatological discontinuities present in the NCEP/NCAR reanalysis temperature due to the introduction of satellite data, Clim. Dyn., 21, 309-316.

Thompson, D. W. J., and S. Solomon (2002), Interpretation of recent Southern Hemisphere climate change, Science, 296, 895-899.

Trenberth, K. E., and A. Solomon (1994), Implications of global atmospheric spatial spectra for processing and displaying data, J. Clim., 6, $531-545$
Turner, J., G. J. Marshall, and T. A. Lachlan-Cope (1998), Analysis of synoptic-scale low pressure systems within the Antarctic Peninsula sector of the circumpolar trough, Int. J. Climatol., 18, 253-280.

van den Broeke, M. R. (2000), On the interpretation of Antarctic temperature trends, J. Clim., 13, 3885-3889.

van Loon, H., and D. J. Shea (1987), The Southern Oscillation, VI, Anomalies of sea level pressure on the Southern Hemisphere and of Pacific sea surface temperature during the development of a warm event, Mon. Weather Rev., 115, 370-379.

Villalba, R., E. R. Cook, R. D. D’Arrigo, G. C. Jacoby, P. D. Jones, M. S. Salinger, and J. Palmer (1997), Sea-level pressure variability around Antarctica since A.D. 1750 inferred from sub-Antarctic tree-ring records, Clim. Dyn., 13, 375-390.

Wen, J. H., J. C. Kang, D. L. Wang, B. Sun, Z. Q. Li, and J. Li (2001), Snow density and stratigraphy at LGB65 in Princess Elizabeth Land, east Antarctica, J. Glaciol. Geocry., 23, 156-163.

White, W. B., and R. G. Peterson (1996), An Antarctic circumpolar wave in surface pressure, wind, temperature and sea-ice extent, Nature, 380, $699-702$.

Xiao, C., J. Ren, D. Qin, Z. Li, W. Sun, and I. Allison (2001), Complexity of climate regime over the Lambert Glacier Basin: Firn core evidences, J. Glaciol, 147, 160-162.

Zhang, M. J., Z. Q. Li, C. D. Xiao, D. H. Qin, H. A. Yang, J. C. Kang, and J. Li (2002), A continuous 250-year record of volcanic activity from Princess Elizabeth Land, east Antarctica, Antarct. Sci., 14(1), 55-60.

Z. Li, D. Qin, and M. Zhang, Cold and Arid Regions Environmental and Engineering Research Institute, Chinese Academy of Sciences, Lanzhou 730000, China.

P. A. Mayewski and Y. Yan, Climate Change Institute, University of Maine, Orono, ME 04469, USA.

C. Xiao, Chinese Academy of Meteorological Science, Beijing 100081, China. (cdxiao@cams.cma.gov.cn) 

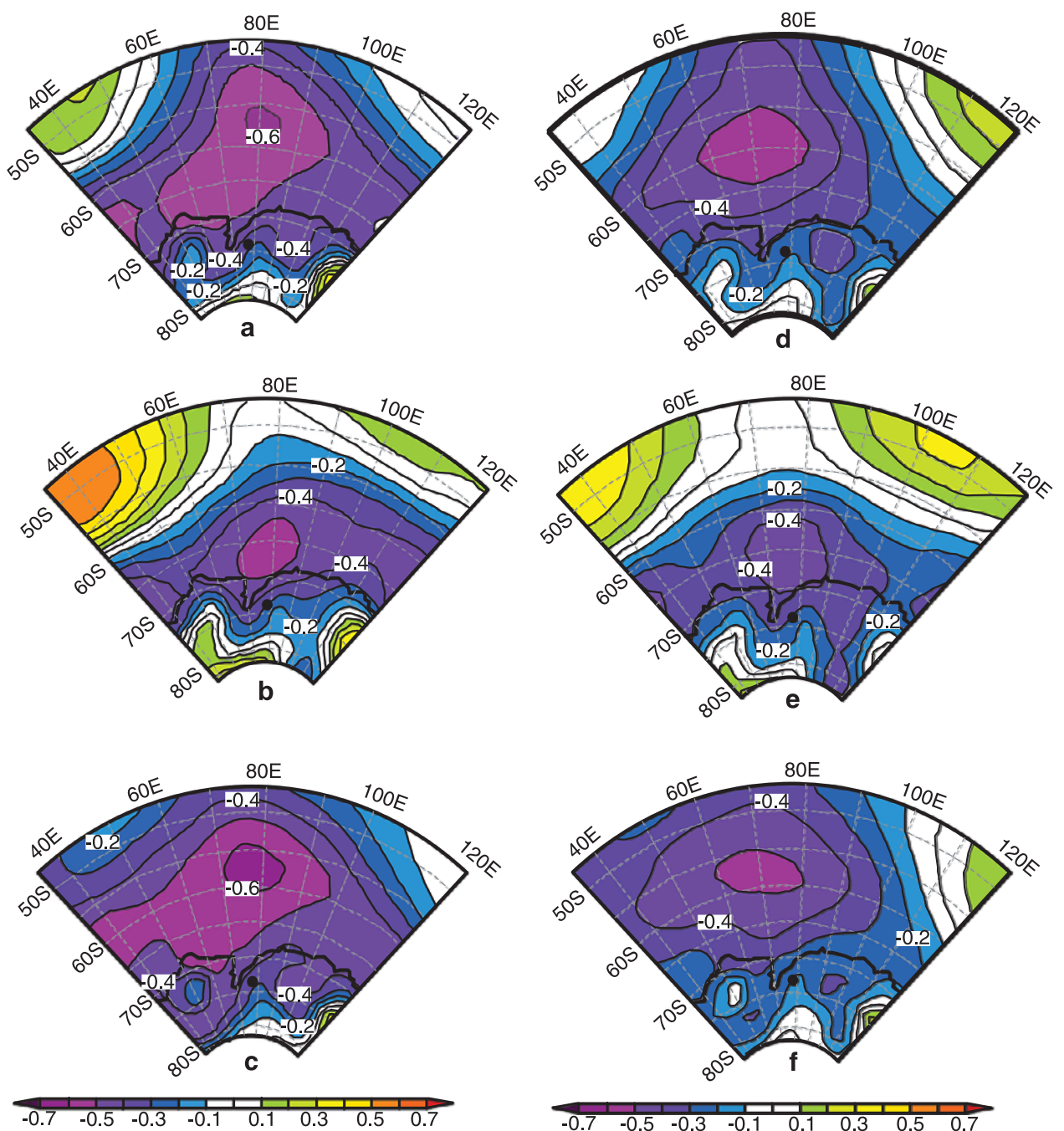

Figure 4. $(\mathrm{a}-\mathrm{c})$ Spatial correlation patterns from the NCEP/NCAR reanalyses between LGB65 EOF1 and SLP in the annual, summer (October to March) and winter (April to September) basis, respectively, for the period 1968-1996; (d-f) same as Figures 4a-4c but for LGB65 sodium. The black dot represents the location of LGB65. 